ribs the liver dullness seems to extend upwards into the axilla and the resistance to the fingers is increased. No definite change in the breath sounds beyoud some lessening over the dull area. $X$-ray evidence showed a large cyst, abont 4 to 5 inches in diameter, present in the axillary line, just above the diaphragm on the right side. A beautifully clear outline was shown and there was no possible doubt as to the nature of the disease. No blood cell changes. There was a shadow at the root of the lung of small size. The radiologist reported that this was due to inflammatory thickening around a bronchus. Operation revealed a degenerated cyst full of odourless pus and cyst débris. The patient has since developed phthisis.

2. F. F., aged 38, sailor, admitted May, 1914, with pleural 2. F. F., aged 38, sailor, admitted May, 1914, with pleural
effusion. effusion. He had a history of left-sided pneumonia and pleurisy for the last eighteen months. Complained of cough and increasing weakness. After aspiration there remained tome dullness below thire rib in front. The pleural fiuid contained polynuclear cells. He was discharged at the end of
three weeks relieved. Readmitted May, 1915. He had lost three weeks relieved. Readmitted May, 1915. He had lost left side. Movement on left side restricted. The heirt was displaced to the right, 3 in. from. mid-sternal line. There was fluid in the left pleura. There was evidence of consolidation. of the lung in front, from the clavicle to the nipple line. Crepitations could be heard at the base of the left lung, The right lung was clear. The radiologist reported that the right lung was healthy throughout. The heart was displaced to right; the left lung co dense all over. hesseuing a litle at apex and bese and mos lobe. Later he reported a rounded deeper shadow, the maximum depth being in the position of the left nipple. June 2nd, lung still clear. Later in June it was found that the pleura openel aud a large quavtity of hydatid material the pleura opeued aud a large quantity of hydatid material was discovered, When furst admitted his temperature fluctuated between $101.8^{\circ}$ and normal ; later it remained normal till
just before the operation, but was never so high as on admission. just before the operation, but was never so high as on admission. period of eighteen months or more. He had a positive Wassermann reaction, and the general opinion of the staff was that the lung was gyphilitic. No eosinophilia was found in repeated examinations, and in spite of a normal temperatire the physical signs did not improve. At the time he first came under my care I made a diaguosis of cyst, but I was unable to induce a surgeou to make a thorough exploration of his chest. It was only the subsequent occurrence of an empyema that led to an operation.

3. J. L., labourer, aged 42, admitted October 22nd, 1918, complaining of pain in lower right anterior chest, worse on taking plaining of pain in lower right anterior chest, worse on taking a deep breath; he sought advice on this account. Temperato position and sounds; general health always good-he was to position and sounds; general health always good-he was
at work up to the day of admission. Cough very little. On examination no pleuritic rub was found. There was a circum scribed area of dullness in the lower right chest, with a slightly more resonant area between the lung and liver dullness in th auterior axillary line margin and extending upwards about four inches. The transition from dullness to resonance was sharp. Breath sounds over dull area weak, no adventitious sounds heard, and no bronchial breathing. $X$ rays showed a clearly defined cyst occupying a large part of the lung, the radiologist estimating this as half the lung. No eosinophilia. Refused operation, as he did not consider it necessary; be is not inconvenienced at all.

Conclusions.

It will be apparent that hydatid cyst may simulate many lung diseases, and to discuss differential diagnosis in detail would be to discuss the character of almost every known disease of the thorax. Moreover, it is clear that a cyst so rárely gives rise to pressure synutoms that the diagnosis must depend on the history and $x$-ray evidence.

\section{VOLVULUS OF THE SMALL INTESTINE FOLLOWING ILEO-COLOSTOMY.}

BY

NORMAN DUGGAN, M.B., Ch.B.VIct., F.R.C.S.Eng., WORCESTER.

The following case seems worthy of record, owing to the comparative rarity of the condition, and the successful result of operation.

Mrs. G., aged 62, had for three years suffered from progressive loss of weight, increasing coustipation, and frequent attacks of severe indigestion and abdominal pain. When first seen, in the autumn of 1919 , she was leading a semi-invalid life, and looked very thin and jll. There were no definite signs of abdominal visease, but operation was advised in view of the possibility of cancer.

First Operation : Ileo-colostomy.

Laparotomy on December 7 th, 1919, revealed no growth, but there was marked visceroptosis, and the colon was thin and atrophic. Ileo colostomy was performed by lateral anastomo si of the closed and divided lower end of the ileum to the pelvic colon. The patient made a good recovery from the operation; the bowels acted freely, pain and indigestion were relieved, and in the spring of this year she was walking up to eight miles a day. A post-operative hernia was controlled efficiently by a Salt's corset-belt.

Second Operation (for Volvulus).

She remained in improved health till June 26th, 1920 ; on this day she was seized with sudden acute abdominal pain, which gradually became worse. When seen next day, the abdomen was slightly distended and tender, but not rigid; the tongue dry and furred, and the pulse feeble and irregular. She had passed some tatus, but no faeces. She was evidently suffering passed some tatus, but no faeces. She was evidently suffering palliative measures were tried first. No result followed a large turpentiue enema, and on the third day from the onset vomiting set in. Operation was then undertaken as a last resort, though her condition was desperate. Under open ether anaesthesia (given by my partner Dr. W. E. Moore Ede), preceded by morphine and atropine, two pints of saline were given intravenously, and the abdomen opened by a median incision below the umbilicus. A twisted mass of intestine, black and gangrenous, the size of a fetal head, was found in the pelvis. The peritoneal cavity contained a quantity of turbid fluid with a strong faecal odour.

The mass proved to be a volvulus of the lower end of the ileum caused by a short cord-like adhesion between two folds of mesentery. As the gut involved was already gangrenous, the intestine above and below was divided between clamps, and a wedge of mesentery resected, the whole specimen being thus wedge of mesentery resected, the whole specimen being thus
removed without attempting to untwist the volvulus. Even so removed without attempting to untwist the volvulus. Fiven so the gangrenous portion burst in the necessary handling and
distributed its contents in the wound. The length of gut removed was two feet, and the volvulus The length of gut removed was two feet, and the volvulus had two complete
revolutions on its axis. The cut ends of intestine were united by an end-to-end anstomosis, two layers of catgut sutures being used; the peritoneum was cleansed by dry swabbing, and the wound closed by through-and-through silkworm sutures.

The patient made an excellent recovery, shock being combated by the intravenous saliue given before the operation, and by frequent rectal saline injections during the twenty-four hours after. In the second week some troublesome diarrhoea, with undigested food in the faeces, was arrested by the use of a mixture containing hydrochloric acid and malt extract. The besn expected after the gross soiling of the wound at the operaben expected after the gross soiling of the wound at the
tion. There was never any sign of peritoneal infection.

The patient was up i i a month, and able to walk two miles in six weeks from the date of operation. Since then her progress has been steady; she looks and feels well, is gaining weight, and the bowels act regularly without pain.

Strangulation of a coil of intestine, which, following an ileo-colostomy, has slipped through the gap between the mesentery of the ileum and that of the pelvic colon, is a well recognized accident; and all authorities therefore recommend that the gap be closed by a suture to prevent the occurrence of this form of internal hernia. This had been done at the first operation in the case now recorded, but when the acute obstruction occurred, it was thought that the suture had possibly given way.

Operation, however, showed that the gap remained closed, and that the condition was due to a volvulus. Tho adhesion giving rise to the volvulus was no doubt a sequel of the first operation-ileo-colostomy.

\section{ftlemuranda:}

\section{MEDICAL, SURGICAL, OBS'TETRICAL.}

\section{TRANSPOSITION OF VISCERA IN TWO MEMBERS} OF ONE FAMILY.

Transposition of viscera is a condition not often met with, and two cases of transposed viscera occurring in members of one family must be so rare that $I$ think the following notes are wortly of publication.

When I was carrying out a medical inspection at a school in Somerset in November, 1919, a girl, aged 12, was presented for routine examination. Upon inspection of her chest, the cardiac impulse was visible just inside the right nipple line; percussion and auscultation showed that the heart was transposed. The abdomen was then examined, and it was found that the stomach, liver, and spleen were trausposed also. The mother of the girl, who was present at the examination, then informed me that the girl's brother, aged 10, "had his heart on the wrong side." I examined this boy the next day, and found that in his case, too, the lieart, stomach, liver, and spleen were transposed. Both clildren appeared to be quite liealthy. 